\title{
Leukocidin genes lukF-P83 and lukM are associated with Staphylococcus aureus clonal complexes 151, 479 and 133 isolated from bovine udder infections in Thuringia, Germany
}

\author{
Katharina Schlotter ${ }^{1 *}$, Ralf Ehricht ${ }^{2 \dagger}$, Helmut Hotzel ${ }^{3 \dagger}$, Stefan Monecke ${ }^{2,4 \dagger}$, Martin Pfeffer ${ }^{5 \dagger}$ and Karsten Donat ${ }^{1 \dagger}$
}

\begin{abstract}
Staphylococcus aureus is one of the most important causal agents of bovine mastitis. Population studies on bovine Staphylococcus aureus isolates have identified considerable genetic heterogeneity among strains causing mastitis. The aim of this study was to investigate the contribution of different clonal complexes and the occurrence of virulence factors and resistance determinants within bovine Staphylococcus aureus isolates.

A total of 189 Staphylococcus aureus isolates obtained from milk samples of 34 dairy herds in the German Federal State of Thuringia were characterised by microarray technology.

The isolates were assigned to eleven different clonal complexes with CC151, CC479 and CC133 being dominant (together $80.5 \%$ ). The methicillin resistance gene mecA was found in four isolates (2.1\%), which belonged to CC398. Enterotoxin genes could be detected in $79.3 \%$ of analysed Staphylococcus aureus and 19 isolates (10.1\%) harboured a distinct allele of the toxic shock syndrome toxin gene, tst-RF122. The most striking finding of the present study was that almost all except one isolate (151/152) belonging to CC151, CC479 and CC133 harboured the leukocidin genes lukF-P83 and lukM, whereas no further isolates from other lineages possessed these genes.

The consistent occurrence of lukF-P83/lukM in the dominating clonal complexes suggests an essential role of this leukocidin in the etiology of bovine mastitis.
\end{abstract}

\section{Background}

Staphylococcus (S.) aureus is one of the most common etiological agents of bovine mastitis [1]. In the German Federal State of Brandenburg, S. aureus could be detected in $21.8 \%$ of all bacteriologically positive milk samples [2]. Similar observations were made in Belgium [3]. Some sequence types (ST) are mainly associated with cattle, whereas other strains are observed in a variety of hosts including humans [4]. Studies of the molecular epidemiology of $S$. aureus suggest that diverse strains differ in their success to cause intramammary infections in cows $[1,5]$. Furthermore, the carriage of different virulence factors like enterotoxins and leukocidin

\footnotetext{
* Correspondence: kschlotter@thueringertierseuchenkasse.de

${ }^{\dagger}$ Equal contributors

'Thüringer Tierseuchenkasse (Livestock Health Service \& Insurance Agency of the State of Thuringia), Victor-Goerttler-Straße 4, 07745 Jena, Germany Full list of author information is available at the end of the article
}

increases the genetic heterogeneity in mastitis-causing strains. Recently published results suggest that the leukocidin LukF-P83/LukM is involved in pathogenesis of staphylococcal mastitis [6-8]. This bicomponent leukocidin is present in the majority of $S$. aureus isolates from bovine milk samples and genes coding this leukocidin seem to be exclusively harboured by strains associated with mastitis in ruminants $[9,10]$. Like the human Panton-Valentine leukocidin (PVL), LukF-P83/LukM consists of two separate components $\mathrm{S}$ and $\mathrm{F}$, which build oligomeric pores in the membrane of phagocytes and thus act as cytolytic toxins [7]. It is the most active $S$. aureus leukotoxin on bovine neutrophils [6] and may influence the severity of disease [11].

The present survey is based on a former study on the application of the microarray-technology on bovine $S$. aureus isolates [12]. The microarray used in this previous study was refined and while the focus of this first

\section{Biomed Central}


study was on sequence variations in different genes, the present investigation is focusing on the distribution and abundance of different $S$. aureus clonal complexes (CC) in 34 dairy herds in the German Federal state of Thuringia. Another aim of this present survey was to investigate the connection between $\mathrm{CC}$ and the virulence and antibiotic resistance gene profile of bovine $S$. aureus.

\section{Materials and Methods}

\section{Isolation of S. aureus strains and DNA preparation}

Quarter milk samples from all milk-producing cows of 34 farms were taken twice at intervals of at least eight weeks, whereas cows with clinical mastitis were excluded from sampling. In this way, 81567 quarter milk samples from 20838 clinically healthy cows were obtained (Table 1). Because of the dry cow period, 7476 of these cows were sampled once and 6681 cows were sampled twice. Cultivation from milk samples was done according to standard procedure [13] in the laboratory of the Livestock Health Service \& Insurance Agency of the State of Thuringia. Specimens were spread on esculin blood agar (Oxoid, Wesel, Germany) and incubated at $37^{\circ} \mathrm{C}$. The plates were examined after 24 and $48 \mathrm{~h}$ of incubation. Single colonies were picked for further subculturing. Screening for clumping factor and coagulase was performed using Staphaurex Plus (Remel, Lenexa, USA) and rabbit plasma (BioMerieux, Marcy-l'Étoile, France). To limit inclusion of $S$. aureus contaminants, only pure cultures above $1000 \mathrm{cfu} / \mathrm{mL}$ were used for further investigations. 189 out of 1902 detected S. aureus isolates, usually three isolates per herd sampling, were selected considering colony morphology (haemolysis, pigmentation) based on following rules:

a. In cases of unique morphology: three isolates randomly selected

b. In cases of heterogeneous morphology: one isolate of each most prevalent type.

Thereafter, the isolates were comprehensively characterised using microarray analysis.

An inoculation loop of $S$. aureus grown on esculin blood agar at $37^{\circ} \mathrm{C}$ overnight was resuspended in $300 \mu \mathrm{L}$ of phosphate buffered saline. Genomic DNA was prepared after enzymatic lysis using lysis buffer and lysis enhancer (both from StaphyType Kit, Alere Technologies $\mathrm{GmbH}$, Jena, Germany). After incubation $\left(1 \mathrm{~h}, 37^{\circ} \mathrm{C}\right.$, $550 \mathrm{rpm}$ ), $40 \mu \mathrm{L}$ proteinase $\mathrm{K}$ and $200 \mu \mathrm{L}$ binding buffer (both from High Pure PCR Template Preparation Kit; Roche Diagnostics, Mannheim, Germany) were added. After a second incubation period $\left(10 \mathrm{~min}, 72^{\circ} \mathrm{C}\right.$, $550 \mathrm{rpm}$ ) the samples were processed using the device of High Pure PCR Template Preparation Kit (Roche Diagnostics) according to the instructions of the manufacturer.

\section{Amplification, labelling, and array hybridisations}

The DNA microarray of the StaphyType Kit (Alere Technologies $\mathrm{GmbH}$ ) used in the present study covers 334 different target sequences, corresponding to, depending on the nomenclature applied, approximately 170 distinct genes and their allelic variants. It includes species markers, resistance genes, exotoxins, MSCRAMM (microbial surface components recognizing adhesive matrix molecules) genes, as well as SCCmec, capsule and agr group typing markers. The targets, related protocols, data interpretation and evaluation procedures used have been described previously [14].

An iterated linear primer elongation with one primer per target was used for the simultaneous amplification of all targets. Within this step, amplicons were labelled by incorporation of biotin-16-dUTP. After denaturation, the sample was hybridised to the array followed by washing and blocking steps. Horseradish-peroxidasestreptavidin conjugate was added. After further incubation and washing steps, hybridisations were visualised by using a precipitation dye. Finally, an image of the microarray was taken and automatically analysed using a designated reader and software (Alere Technologies $\mathrm{GmbH})$.

The affiliation of isolates to CC as defined by MLST was determined by an automated software comparison of hybridisation profiles to a collection of reference strains previously characterised by MLST. The suitability of this method to assign isolates to $\mathrm{CC}$ was shown by former investigations [15].

\section{Statistical calculations}

The calculation software SPSS 15.0 for Windows (Fa. SPSS Inc., Illinois, Chicago, USA) was used for statistical calculations. CC were classified according to presence of lukF-P83/lukM. A $\mathrm{k}^{*} 2$ contingency table was tested for homogeneity of frequencies using chi-squares procedure (exact significance) and a level of significance of $p \leq 0.01$.

\section{Measuring leukocidin concentration in lukF-P83/lukM positive isolates}

To clarify if the expression of $l u k F-P 83 / l u k M$ is possible at least under in vitro conditions, we measured the amount of LukF-P83/LukM in culture supernatant of 15 lukF-P83/lukM positive isolates as described by Monecke et al. [16].

\section{Results}

Species confirmation of S. aureus

Using microarray analysis, 189 isolates were examined for $S$. aureus specific markers like catalase (katA), coagulase (coa), protein A (spa) and staphylococcal accessory regulator A (sarA). All isolates were thus confirmed as $S$. aureus. 
Table 1 Number of cows, proportion of S. aureus infected cows and frequencies of the different CC

\begin{tabular}{|c|c|c|c|c|c|c|c|c|c|c|c|c|c|}
\hline Herd & Investigated cows & Proportion of S. aureus infected cows & CC151 & CC479 & CC133 & CC97 & CC398 & CC9 & CC20 & CC45 & CC101 & $\mathrm{CC7}$ & $\mathrm{CC50}$ \\
\hline & $\mathbf{n}$ & $\%$ & $\mathbf{n}$ & $\mathbf{n}$ & $\mathbf{n}$ & $\mathbf{n}$ & $\mathbf{n}$ & $\mathbf{n}$ & $\mathbf{n}$ & $\mathbf{n}$ & $\mathbf{n}$ & $\mathbf{n}$ & $\mathbf{n}$ \\
\hline 1 & 79 & 50.00 & & & & 6 & & & & & & & \\
\hline 2 & 273 & 18.38 & 3 & & & & & & 3 & & & & \\
\hline 3 & 117 & 33.33 & 6 & & & & & & & & & & \\
\hline 4 & 322 & 9.91 & 5 & 1 & & & & & & & & & \\
\hline 5 & 1156 & 6.32 & 4 & 1 & & & 1 & & & & & & \\
\hline 6 & 645 & 3.04 & 1 & 1 & 4 & & & & & & & & \\
\hline 7 & 1111 & 6.29 & 1 & & 3 & & & & & & 2 & & \\
\hline 8 & 2172 & 13.22 & 1 & 3 & & & 2 & & & & & & \\
\hline 9 & 1482 & 2.37 & & & 3 & & 3 & & & & & & \\
\hline 10 & 699 & 2.40 & & 4 & 2 & & & & & & & & \\
\hline 11 & 349 & 23.21 & 5 & & 1 & & & & & & & & \\
\hline 12 & 75 & 4.00 & 1 & 1 & & & & & & & & & \\
\hline 13 & 678 & 0.63 & 1 & & 1 & & & & & 1 & & & \\
\hline 14 & 773 & 8.29 & 5 & 1 & & & & & & & & & \\
\hline 15 & 739 & 6.04 & & 3 & & & & 3 & & & & & \\
\hline 16 & 125 & 6.98 & 6 & & & & & & & & & & \\
\hline 17 & 233 & 8.23 & 3 & 2 & 1 & & & & & & & & \\
\hline 18 & 354 & 16.80 & 3 & 1 & 2 & & & & & & & & \\
\hline 19 & 684 & 12.27 & 4 & 2 & & & & & & & & & \\
\hline 20 & 714 & 11.31 & 6 & & & & & & & & & & \\
\hline 21 & 259 & 7.88 & 5 & & 1 & & & & & & & & \\
\hline 22 & 1029 & 3.77 & 6 & & & & & & & & & & \\
\hline 23 & 194 & 8.47 & 3 & 3 & & & & & & & & & \\
\hline 24 & 996 & 0.31 & & 1 & & & & & & & & 1 & \\
\hline 25 & 1738 & 18.89 & & 2 & 2 & & & & 2 & & & & \\
\hline 26 & 749 & 14.12 & 1 & & & 2 & & 2 & & & 1 & & \\
\hline 27 & 32 & 40.00 & 2 & & & & & & & 4 & & & \\
\hline 28 & 863 & 14.71 & 4 & 1 & & & 1 & & & & & & \\
\hline 29 & 74 & 19.51 & 5 & & & & & & & & & & 1 \\
\hline 30 & 410 & 12.27 & & 6 & & & & & & & & & \\
\hline 31 & 332 & 0.84 & 1 & & & 1 & & & & & & & \\
\hline 32 & 380 & 13.65 & 5 & & & & 1 & & & & & & \\
\hline 33 & 666 & 4.71 & 5 & & 1 & & & & & & & & \\
\hline 34 & 336 & 12.12 & 6 & & & & & & & & & & \\
\hline$\sum$ & 20838 & 9.19 & 98 & 33 & 21 & 9 & 8 & 5 & 5 & 5 & 3 & 1 & 1 \\
\hline
\end{tabular}

\section{Affiliation to CC}

The 189 isolates were clustered into eleven different CC (Table 1$) .80 .5 \%(n=152)$ of all isolates were assigned to CC151 $(n=98)$, CC479 $(n=33)$ and CC133 $(n=21)$. In 18 out of the 34 herds, all investigated isolates exclusively belonged to these three CC (Table 1). Furthermore, CC97 $(n=9)$, CC398 $(n=8)$, CC9 $(n=5)$, CC20 $(n=5), \operatorname{CC} 45(n=5), \operatorname{CC} 101(n=3), \operatorname{CC} 7(n=1)$ and CC50 $(n=1)$ were detected in this study.
All isolates of CC133, CC97, CC398, CC20, CC45, CC101 and CC7 belonged to agr group I, whereas CC151, CC479 and CC9 belonged to agr group II. The CC50 isolate was part of agr group IV.

\section{Leukocidin carriage}

The genes encoding for Panton-Valentine leukocidin (lukS/F-PVL) were not found in this study, but the genes lukF-P83 and lukM were detected in 151 out of 189 
isolates (79.9\%) belonging to CC151, CC479 and CC133 (Table 2). With the exception of one CC479 isolate, all isolates belonging to these $\mathrm{CC}$ possessed the genes encoding for the LukF-P83/LukM leukocidin, and none of the other CC did. Frequencies of $\mathrm{CC}$ with or without lukF-P83/lukM differed significantly $(p<0.01)$. The expressed leukotoxin could be detected in culture supernatant of all 15 tested lukF-P83/lukM positive isolates whereas the toxin was not detected in isolates which were genotypically negative for $l u k F-P 83 / l u k M$.

The genes encoding the leukocidin $\mathrm{LukD} / \mathrm{E}$ were detected in all isolates belonging to CC7, CC20, CC50, CC97, CC101, CC133, CC151 and CC479, although some of these isolates gave variable, weak or negative results for either $l u k D$ or $l u k E$ (data not shown). This might be regarded as an indicator for sequence variations. Leukocidin genes $l u k D$ and $l u k E$ were not found in isolates belonging to CC398, CC9 and CC45 (Table 2).

\section{Superantigen carriage}

Nineteen out of 189 isolates affiliated to CC151 harboured a distinct allele of the toxic shock syndrome toxin gene as known from the genome sequence of strain RF122 [GenBank: AJ938182], designated here as tst-RF122 (Table 2). Another allele of tst-1, as observed in isolates from humans (such as in BA000017.4), was present in only one sample belonging to CC45.

Enterotoxin genes were found in $78.3 \%$ of analysed isolates. Genes of the egc-enterotoxin gene cluster ( $\mathrm{seg}+$ $s e i+s e m+s e n+s e o+s e u / y$ ) were found most frequently, in 147 isolates belonging to CC9, CC20, CC45, CC50, CC151 and CC479.

The genes encoding for the classical enterotoxins A-C (sea, seb, sec) were comparatively rare (Table 2). The enterotoxin A gene sea was only found in the single $\mathrm{CC} 7$ isolate, being present in an allele as previously described from the CC5 strain N315. Twenty-three out of 189 isolates harboured sec and sel, which are commonly located on pathogenicity island SaPIbov [17]. All sec/sel positive isolates belonging to $\mathrm{CC151}(n=18)$ also harboured tstRF122. seb was detected in four isolates combined with sec. The genes encoding enterotoxin $\mathrm{D}, \mathrm{E}, \mathrm{H}, \mathrm{J}, \mathrm{K}, \mathrm{Q}$ and $\mathrm{R}$ were not found among isolates tested.

\section{Other virulence genes}

The gene encoding staphylokinase (sak) was only detected in all three isolates belonging to CC101 and one isolate of each $\mathrm{CC} 9, \mathrm{CC} 45$, and $\mathrm{CC} 7$, representing $3.2 \%$ of all samples (Table 2).

The majority of isolates (89.9\%) possessed the haemolysin beta gene $h l b$. Genes for haemolysins alpha, delta, and gamma ( $h l a, h l d$, and the $h l g$-locus comprised of $l u k S, l u k F$, and $h \lg A$ ) were present in all isolates.

Exfoliative toxin genes (etA, etB, etD) and epidermal cell differentiation inhibitor genes $(\operatorname{edin} A-C)$ were not detected.

\section{Antibiotic resistance genes}

The methicillin resistance gene $m e c A$ was found in four isolates (2.1\%), which all belonged to CC398 (Table 2). They also carried the $\beta$-lactamase operon blaZ, blaI and blaR and the tetracycline resistance determinant tetM. The gene tetK, which also confers resistance to tetracyclines, was detected in three $m e c A$-positive CC398 isolates. Among the other isolates, resistance genes were generally rare. Beside the CC398-MRSA isolates, seventeen further isolates harboured the $\beta$-lactamase gene blaZ. The gene was detected in all isolates belonging to CC9, CC20 and CC398 (Table 2). Moreover, blaZ was found in one isolate of each CC151, CC45 and CC7. The gene tet $M$ was found in three methicillin-susceptible

Table 2 Presence of genes encoding leukocidins, superantigenes, staphylokinase, as well as of resistance determinants

\begin{tabular}{lcccccccccccccccccccc}
\hline CC & $\mathbf{n}$ & lukF-P83 & lukM & lukD & lukE & tst-1 & tst-RF122 & sea & seb & sec & sel & egc & sak & mecA & blaZ & fosB & tetK & tetM & fexA & cat \\
\hline CC151 & $\mathbf{9 8}$ & $\mathbf{9 8}$ & $\mathbf{9 8}$ & $\mathbf{9 8}$ & $\mathbf{9 4}$ & 0 & $\mathbf{1 9}$ & 0 & $\mathbf{4}$ & $\mathbf{1 8}$ & $\mathbf{1 8}$ & $\mathbf{9 8}$ & 0 & 0 & $\mathbf{1}$ & $\mathbf{3}$ & 0 & 0 & 0 & $\mathbf{1}$ \\
CC479 & $\mathbf{3 3}$ & $\mathbf{3 2}$ & $\mathbf{3 2}$ & $\mathbf{3 3}$ & $\mathbf{3 0}$ & 0 & 0 & 0 & 0 & 0 & 0 & $\mathbf{3 3}$ & 0 & 0 & 0 & $\mathbf{2}$ & 0 & 0 & $\mathbf{2}$ & 0 \\
CC133 & $\mathbf{2 1}$ & $\mathbf{2 1}$ & $\mathbf{2 1}$ & $\mathbf{2 1}$ & $\mathbf{2}$ & 0 & 0 & 0 & 0 & 0 & 0 & 0 & 0 & 0 & 0 & $\mathbf{2 0}$ & 0 & 0 & $\mathbf{3}$ & 0 \\
CC97 & $\mathbf{9}$ & 0 & 0 & $\mathbf{9}$ & $\mathbf{7}$ & 0 & 0 & 0 & 0 & 0 & 0 & 0 & 0 & 0 & 0 & $\mathbf{2}$ & 0 & 0 & 0 & 0 \\
CC398 & $\mathbf{8}$ & 0 & 0 & 0 & 0 & 0 & 0 & 0 & 0 & 0 & 0 & 0 & 0 & $\mathbf{4}$ & $\mathbf{8}$ & 0 & $\mathbf{3}$ & $\mathbf{7}$ & $\mathbf{3}$ & 0 \\
CC9 & $\mathbf{5}$ & 0 & 0 & 0 & 0 & 0 & 0 & 0 & 0 & 0 & 0 & $\mathbf{5}$ & $\mathbf{1}$ & 0 & $\mathbf{5}$ & $\mathbf{5}$ & 0 & 0 & 0 & 0 \\
CC20 & $\mathbf{5}$ & 0 & 0 & 0 & $\mathbf{5}$ & 0 & 0 & 0 & 0 & 0 & 0 & $\mathbf{5}$ & 0 & 0 & $\mathbf{5}$ & $\mathbf{5}$ & 0 & 0 & 0 & 0 \\
CC45 & $\mathbf{5}$ & 0 & 0 & 0 & 0 & $\mathbf{1}$ & 0 & 0 & 0 & $\mathbf{5}$ & $\mathbf{5}$ & $\mathbf{5}$ & $\mathbf{1}$ & 0 & $\mathbf{1}$ & 0 & 0 & 0 & 0 & 0 \\
CC101 & $\mathbf{3}$ & 0 & 0 & $\mathbf{3}$ & $\mathbf{3}$ & 0 & 0 & 0 & 0 & 0 & 0 & 0 & $\mathbf{3}$ & 0 & 0 & $\mathbf{3}$ & 0 & 0 & 0 & 0 \\
CC7 & $\mathbf{1}$ & 0 & 0 & $\mathbf{1}$ & $\mathbf{1}$ & 0 & 0 & $\mathbf{1}$ & 0 & 0 & 0 & 0 & $\mathbf{1}$ & 0 & $\mathbf{1}$ & 0 & 0 & 0 & 0 & 0 \\
CC50 & $\mathbf{1}$ & 0 & 0 & $\mathbf{1}$ & $\mathbf{1}$ & 0 & 0 & 0 & 0 & 0 & 0 & $\mathbf{1}$ & 0 & 0 & 0 & 0 & 0 & 0 & 0 & 0 \\
$\sum$ & $\mathbf{1 8 9}$ & $\mathbf{1 5 1}$ & $\mathbf{1 5 1}$ & $\mathbf{1 6 6}$ & $\mathbf{1 4 3}$ & $\mathbf{1}$ & $\mathbf{1 9}$ & $\mathbf{1}$ & $\mathbf{4}$ & $\mathbf{2 3}$ & $\mathbf{2 3}$ & $\mathbf{1 4 7}$ & $\mathbf{6}$ & $\mathbf{0}$ & $\mathbf{2 1}$ & $\mathbf{4 0}$ & $\mathbf{3}$ & $\mathbf{7}$ & $\mathbf{8}$ & $\mathbf{1}$ \\
\hline
\end{tabular}


CC398 isolates. Thirty-nine methicillin susceptible $S$. aureus (MSSA) isolates harboured the putative fosfomycin/bleomycin resistance gene fos $B$. The chloramphenicol resistance determinant fexA was found eight times (Table 2); one CC151 isolate contained another chloramphenicol resistance determinant, cat. Another CC151 isolate harboured the macrolide resistance determinant $m s r A$. The streptogramin resistance gene $v g a A$ and aacA-aphD, which confers resistance to aminoglycosides gentamicin and tobramycin, were detected in one CC398 isolate each. None of the other resistance genes represented on the array was found.

\section{Discussion and conclusions}

Previously conducted studies in the USA, the UK, Norway, Switzerland and Chile showed that only a few $S$. aureus genotypes cause the majority of bovine mastitis cases [1,18-21]. In our study, CC151, CC479 and CC133 were the dominating $\mathrm{CC}$. In 18 out of 34 participating herds, only these three $\mathrm{CC}$ could be detected, while only in one dairy herd (herd 1) none of these CC was found (Table 1). In this herd of 45 lactating cows, which is an exceptionally small one compared to the other herds, the proportion of $S$. aureus-infected cows was very high (50\%) and all six tested isolates belonged to CC97, which is a $\mathrm{CC}$ known to occur in ungulates.

According to the current state of knowledge, no CC151, CC479 and CC133 isolates were found in humans up to now. While CC151 and CC479 are restricted to cattle $[4,9,21]$, CC133 also occurs in sheep and goats [22]. S. aureus belonging to the other CC, which were only sporadically found in milk samples, are not restricted to a particular host species. CC7, CC9, CC20, CC45 and CC101 were preferentially isolated from human sources [23]. However, their occurrence is also described for different pets and livestock [12,24,25]. CC50 was equally detected in animals [4] as well as in human samples [26]. CC97 is quite frequently found in bovine mastitis, but it can also be detected in human cases [21]. CC398 is of outstanding importance in livestock and can be found in a variety of animal species including poultry, swine, horses and cattle [12,27-29]. Methicillin resistant strains of this CC (CC398-MRSA) have recently received a lot of attention as strains from this lineage are regarded as zoonotic [30,31]. Four $m e c A$-positive strains in this study belonged to CC398 (2.1\% of all tested isolates). Compared with results obtained from German pig herds with MRSA prevalences up to $70.8 \%$ [31-33], the detected prevalence in our cattle study seems low. Our results are in accordance to a previous study reporting a MRSA prevalence of $1.6 \%$ among bovine isolates from Germany and Switzerland [12]. Similar low prevalences of MRSA in the context of bovine mastitis have also been reported from other countries $[34,35]$.

Apart from the $m e c A$-positive isolates, resistance genes were rare. Twenty-one isolates carried blaZ (11.1\%), whereas 20 of these isolates belonged to strains without a distinct host species specificity. Forty isolates (21.2\%) harboured fos $B$. The tetracycline resistance determinant tetM was detected in seven out of eight CC398 isolates $(4 \times$ MRSA, $3 \times$ MSSA). Three tetM-positive MRSA isolates additionally possessed tet $K$. The simultaneous presence of tet $K$ and tet $M$ is more prevalent in MRSA isolates than in MSSA isolates and the strains harbouring both genes displayed higher MIC values than those carrying just one of the genes [36]. The increased resistance to tetracycline seems to be a selective advantage.

The low occurrence of resistance genes in bovine isolates could indicate a lower selective pressure in consequence of a more constricted use of antibiotics in bovine medicine contrary to human medicine. It has to be mentioned that array targets are designed for human isolates. Therefore, certain resistance markers such as ermT, $d$ frK, tet $L$ and $v g a E$ might have remained undetected.

The staphylokinase gene sak was found only sporadically in our study. None of the CC151, CC479 and CC133 isolates carried sak. In contrast, undisrupted $h l b$ was found in the majority of isolates. Similar results were reported by Sung et al. [21]. In human strains, sak is highly prevalent [37] and $h l b$ is usually inactivated by the insertion of phages carrying sea as well as sak, scn and chp in various combinations [38]. The latter authors speculated that the presence of $h l b$, which encodes a phospholipase $\mathrm{C}$, in bovine mastitis provides a higher selective advantage than staphylokinase. The simultaneous occurrence of $s a k$ and undisrupted $h l b$ in five strains could possibly indicate the integration of a phage at an unusual site in the $S$. aureus genome or the presence of mixed populations in which some cells carry the phage while others lack it. One $s a k$ and $h l b$ positive isolate also carried sea. Because of its typical occurrence in human strains, the presence of sak could possibly indicate a human (milker)-to-cow transmission. Particularly with regard to one CC45 isolate in our investigations, such a transfer appears to be probable. This one did not possess undisrupted $h l b$, but carried sak and an allele of tst-1 usually associated with human strains, a combination not found in any other isolate. It cannot be completely excluded that the source of this CC45 isolate was a contamination. However, this source seems unlikely because only pure cultures above $1000 \mathrm{cfu} / \mathrm{mL}$ were used for further investigations.

The most striking finding of the present study was that almost all isolates belonging to CC151, CC479 and CC133 harboured the combination of $l u k M$ and $l u k F-$ P83 while no isolates from the other CC carried these 
genes. The high level of significance between $\mathrm{CC}$ and the presence of this leukocidin indicates a high clinical or epidemiological relevance of this factor. LukM and LukF-P83 are components of a leukocidin originally described in bovine $S$. aureus strain P83. The corresponding genes $l u k M$ and $l u k F-P 83$ lie on the genome of a prophage and are encoded as one operon similar to that of the Panton-Valentine leukocidin [7]. Based on our investigations, the presence of lukF-P83/lukM is strictly associated with certain $S$. aureus lineages. According to the current state of knowledge these lineages are limited to cattle and small ruminants $[4,9,21,22]$.

In recent years, some authors referred to the heterogeneity of different $S$. aureus strains in epidemiology, prognosis and therapy [20,39]. While some strains comparable to Streptococcus agalactiae - behave very contagiously, other strains show the nature of environmental pathogens and can also be detected outside the cows in the stable [40]. Because of the host specificity of certain CC from cattle, other hosts (e.g. milkers, yard dogs or rodents) probably cannot serve as a reservoir. The detection of lukF-P83/lukM in selected isolates of a dairy farm could facilitate an identification of cattleadapted $S$. aureus strains, which can more easily be targeted by infection control programs than strains originating from other sources. Furthermore, the consistent occurrence of lukF-P83/lukM in the dominating CC hypothesises an essential role of this leukocidin on the etiology in bovine mastitis. Up to now, only in vitro investigations regarding the pathogenicity of LukF-P83/ LukM have been made. Rainard et al. [8] investigated the leukotoxic potential of different $S$. aureus strains towards ruminant neutrophils. According to this study, lukF-P83/lukM-positive strains had a significantly higher leukotoxicity than strains without these genes.

In the bovine udder, the presence of these leukocidin genes in S. aureus could be a crucial selective advantage. A leukotoxicity, provided it also exists in vivo, could lead to reduction of host defense and facilitate more rapid colonisation of the bovine udder by pathogens. In addition, the potentially mobile localisation of lukF-P83/ $l u k M$ on the genome of a prophage [7] might also indicate a relevance of the leukocidin for S. aureus in a bovine environment. If a prophage is consistently present in a host population it should be expected that its presence confers some evolutionary advantages. If its integration might cause a disadvantage such as slower replication, $S$. aureus populations without this phage should prevail. If it causes neither advantage nor disadvantage, it should be rather rare as acquisitions as well as loss are random events.

One CC479 isolate did not possess lukF-P83/lukM. This indicates that loss of the prophage from an isolate belonging to one of the dominating CC in the study still might occur. The particular CC479 isolate without lukFP83/lukM was apparently unable to spread during the study period as subsequently, no further $S$. aureus was identified in this herd.

From these observations, analogies to PVL may be drawn. PVL positive $S$. aureus strains have spread worldwide in recent years [37]. While infections caused by PVL negative $S$. aureus strains in persons without health-care-associated risk factors are often asymptomatic, infections with PVL positive strains usually cause severe symptoms in otherwise healthy children and young adults such as recurrent/chronic skin and soft tissue infections or necrotising pneumonia [41]. Similar to PVL, LukF-P83/LukM could determine whether S. aureus behaves as an accidental or as an obligatory pathogen in its respective host organism. LukF-P83/LukM negative strains would then be accidental strains in cattle, possibly being transferred from other species such as humans or rodents into cows. LukF-P83/LukM positive strains could then be regarded as obligatory pathogens to cattle which also implied that they might easily spread and persist in herds. For surveillance a rapid "Point of Care" test for this virulence marker would be a helpful tool.

In conclusion, the strikingly high prevalence of $\mathrm{CC}$ harbouring lukF-P83/lukM leads to the hypothesis, that strains with these genes possess advantages capable to dominate in the spread of the infection within the herd. Although we yet lack the understanding of the underlying mechanism of this selection, we assume that the occurrence of lukF-P83/lukM might have an influence on the severity of bovine mastitis. However, this has to be subject of further investigations. Beyond that, it will be necessary to investigate the geographic distribution and the pathogenic properties of CC of $S$. aureus in other regions, in order to see whether or not the sole detection of $l u k F-P 83 / l u k M$ would be suitable for mastitiscausing $S$. aureus.

\section{Competing interests}

The authors declare that they have no competing interests.

\section{Acknowledgements}

The present study is a part of the project "Investigations on prevalence and adverse effect of udder infections with Staphylococcus aureus in Thuringian dairy herds" of Thüringer Tierseuchenkasse AdöR. It was partly supported by "Landesvereinigung Thüringer Milch e.V.". The authors thank both institutions for supporting. Furthermore the authors would like to thank Karin Klengel, Anke Rüttger, Gesine Kauth, Jana Sachtschal and Elke Müller for their support and technical assistance.

\section{Author details}

${ }^{1}$ Thüringer Tierseuchenkasse (Livestock Health Service \& Insurance Agency of the State of Thuringia), Victor-Goerttler-Straße 4, 07745 Jena, Germany. ${ }^{2}$ Alere Technologies GmbH, Loebstedter Straße 103-105, 07749 Jena, Germany.

${ }^{3}$ Friedrich-Loeffler-Institut, Institute of Bacterial Infections and Zoonoses, Naumburger Straße 96a, 07743 Jena, Germany. ${ }^{4}$ Institute for Medical Microbiology and Hygiene, Faculty of Medicine Carl Gustav Carus, Technical 
University of Dresden, Fiedlerstraße 42, 01307 Dresden, Germany. ${ }^{5}$ Institute of Animal Hygiene and Veterinary Public Health, Centre of Veterinary Public Health, University Leipzig, An den Tierkliniken 1, 04103 Leipzig, Germany.

\section{Authors' contributions}

$\mathrm{KD}$ and $\mathrm{HH}$ conceived the study, and developed its design and coordination. $M P, R E, S M$ and KS participated in study design. KS carried out the bacteriological investigations, DNA preparation and hybridisation. The expression of leukocidin was tested by RE. KD and KS carried out the statistical calculations. The manuscript was drafted by KS and was revised critically by $\mathrm{RE}, \mathrm{HH}, \mathrm{SM}, \mathrm{MP}$, and $\mathrm{KD}$. All authors read and approved the final manuscript.

Received: 31 January 2012 Accepted: 15 May 2012

Published: 15 May 2012

\section{References}

1. Kapur V, Sischo WM, Greer RS, Whittam TS, Musser JM: Molecular population genetic analysis of Staphylococcus aureus recovered from cows. J Clin Microbiol 1995, 33:376-380.

2. Tenhagen BA, Köster G, Wallmann J, Heuwieser W: Prevalence of mastitis pathogens and their resistance against antimicrobial agents in dairy cows in Brandenburg, Germany. J Dairy Sci 2006, 89:2542-2551.

3. Piepers S, de Meulemeester L, de Kruif A, Opsomer G, Barkema HW, de Vliegher S: Prevalence and distribution of mastitis pathogens in subclinically infected dairy cows in Flanders, Belgium. J Dairy Res 2007, 74:478-483.

4. Van den Borne BH, Nielen M, van Schaik G, Melchior MB, Lam TJ, Zadoks RN: Host adaptation of bovine Staphylococcus aureus seems associated with bacteriological cure after lactational antimicrobial treatment. J Dairy Sci 2010, 93:2550-2558.

5. Haveri M, Taponen S, Vuopio-Varkila J, Salmenlinna S, Pyörälä S: Bacterial genotype affects the manifestation and persistence of bovine Staphylococcus aureus intramammary infection. I Clin Microbiol 2005, 43:959-962.

6. Barrio MB, Rainard P, Prévost G: LukM/LukF-PV is the most active Staphylococcus aureus leukotoxin on bovine neutrophils. Microbes Infect 2006, 8:2068-2074

7. Kaneko J, Kamio Y: Bacterial two-component and hetero-heptameric pore-forming cytolytic toxins: structures, pore-forming mechanism, and organization of the genes. Biosci Biotechnol Biochem 2004, 68:981-1003.

8. Rainard P, Corrales JC, Barrio MB, Cochard T, Poutrel B: Leucotoxic activities of Staphylococcus aureus strains isolated from cows, ewes, and goats with mastitis: Importance of LukM/LukF'-PV leucotoxin. Clin Diagn Lab Immunol 2003, 10:272-277.

9. Herron-Olson L, Fitzgerald JR, Musser JM, Kapur V: Molecular correlates of host specialization in Staphylococcus aureus. PLoS One 2007, 2:e1120

10. Yamada T, Tochimaru N, Nakasuji S, Hata E, Kobayashi H, Eguchi M, Kaneko J, Kamio Y, Kaidoh T, Takeuchi S: Leukotoxin family genes in Staphylococcus aureus isolated from domestic animals in prevalence of lukM-lukF-PV genes by bacteriophages in bovine isolates. Vet Microbiol 2005, 110:97-103.

11. Fromageau A, Gilbert FB, Prévost G, Rainard P: Binding of the Staphylococcus aureus leukocidin LukM to its target cells. Microb Pathog 2010, 49:354-362.

12. Monecke $S$, Kuhnert $P$, Hotzel $H$, Slickers $P$, Ehricht R: Microarray based study on virulence-associated genes and resistance determinants of Staphylococcus aureus isolates from cattle. Vet Microbiol 2007, 125:128140

13. Deutsche Veterinärmedizinische Gesellschaft e.V. (DVG), Fachgruppe "Milchhygiene": Leitlinien Entnahme von Milchproben unter antiseptischen Bedingungen und Isolierung und Identifizierung von Mastitiserregern. DVGVerlag: Giessen; 2009.

14. Monecke S, Jatzwauk L, Weber S, Slickers P, Ehricht R: DNA microarraybased genotyping of methicillin-resistant Staphylococcus aureus strains from Eastern Saxony. Clin Microbiol Infect 2008, 14:534-545.

15. Monecke S, Slickers P, Ehricht R: Assignment of Staphylococcus aureus isolates to clonal complexes based on microarray analysis and pattern recognition. FEMS Immunol Med Microbiol 2008, 53:237-251.
16. Monecke S, Buechler J, Ehricht R: Measuring S. aureus exotoxin concentration using protein microarrays with antibodies generated by phage display. In Proceedings of the 21st European Congress of Clinica Microbiology and Infectious Diseases: 7-10 May 2011; Milan [http://aleretechnologies.com/fileadmin/Media/Paper/Poster/Poster-ECCMID_2011_ MILAN_Staph_toxin_antibodies.pdf].

17. Fitzgerald JR, Monday SR, Foster TJ, Bohach GA, Hartigan PJ, Meaney WJ, Smyth CJ: Characterization of a putative pathogenicity island from bovine Staphylococcus aureus encoding multiple superantigens. $J$ Bacteriol 2001, 183:63-70.

18. Fournier C, Kuhnert P, Frey J, Miserez R, Kirchhofer M, Kaufmann T, Steiner A, Graber HU: Bovine Staphylococcus aureus: Association of virulence genes, genotypes and clinical outcome. Res Vet Sci 2008, 85:439-448.

19. Mørk T, Tollersrud T, Kvitle B, Jørgensen HJ, Waage S: Comparison of Staphylococcus aureus genotypes recovered from cases of bovine, ovine, and caprine mastitis. J Clin Microbiol 2005, 43:3979-3984.

20. Smith EM, Green LE, Medley GF, Bird HE, Fox LK, Schukken YH, Kruze JV, Bradley AJ, Zadoks RN, Dowson CG: Multilocus sequence typing of intercontinental bovine Staphylococcus aureus isolates. J Clin Microbiol 2005, 43:4737-4743.

21. Sung JM, Lloyd DH, Lindsay JA: Staphylococcus aureus host specificity: comparative genomics of human versus animal isolates by multi-strain microarray. Microbiology 2008, 154:1949-1959.

22. Smyth DS, Feil EJ, Meaney WJ, Hartigan PJ, Tollersrud T, Fitzgerald JR, Enright MC, Smyth CJ: Molecular genetic typing reveals further insights into the diversity of animal-associated Staphylococcus aureus. J Med Microbiol 2009, 58:1343-1353.

23. McCarthy AJ, Lindsay JA: Genetic variation in Staphylococcus aureus surface and immune evasion genes is lineage associated: implications for vaccine design and host-pathogen interactions. BMC Microbiol 2010, 10:173.

24. Hasman H, Moodley A, Guardabassi L, Stegger M, Skov RL, Aarestrup FM: Spa type distribution in Staphylococcus aureus originating from pigs, cattle and poultry. Vet Microbiol 2010, 141:326-331.

25. Monecke S, Coombs G, Shore AC, Coleman DC, Akpaka P, Borg M, Chow H, Ip M, Jatzwauk L, Jonas D, Kadlec K, Kearns A, Laurent F, O'Brien FG, Pearson J, Ruppelt A, Schwarz S, Scicluna E, Slickers P, Tan HL, Weber S, Ehricht R: A field guide to pandemic, epidemic and sporadic clones of methicillinresistant Staphylococcus aureus. PLoS One 2011, 6:e17936.

26. Conceição T, de Sousa MA, de Lencastre H: Staphylococcal interspersed repeat unit typing of Staphylococcus aureus: evaluation of a new multilocus variable-number tandem-repeat analysis typing method. $J$ Clin Microbiol 2009, 47:1300-1308.

27. Kadlec K, Ehricht R, Monecke S, Steinacker U, Kaspar H, Mankertz J, Schwarz S: Diversity of antimicrobial resistance pheno- and genotypes of methicillin-resistant Staphylococcus aureus ST398 from diseased swine. J Antimicrob Chemother 2009, 64:1156-1164.

28. Walther B, Monecke S, Ruscher C, Friedrich AW, Ehricht R, Slickers P, Soba A, Wleklinski CG, Wieler LH, Lübke-Becker A: Comparative molecular analysis substantiates zoonotic potential of equine methicillin-resistant Staphylococcus aureus. J Clin Microbiol 2009, 47:704-710.

29. Nemati M, Hermans K, Lipinska U, Denis O, Deplano A, Struelens M, Devriese LA, Pasmans F, Haesebrouck F: Antimicrobial resistance of old and recent Staphylococcus aureus isolates from poultry: first detection of livestock-associated methicillin-resistant strain ST398. Antimicrob Agents Chemother 2008, 52:3817-3819.

30. Huijsdens XW, van Dijke BJ, Spalburg E, van Santen-Verheuvel MG, Heck ME, Pluister GN, Voss A, Wannet WJ, de Neeling AJ: Community-acquired MRSA and pig-farming. Ann Clin Microbiol Antimicrob 2006, 5:26.

31. Schwarz S, Kadlec K, Strommenger B: Methicillin-resistant Staphylococcus aureus and Staphylococcus pseudintermedius detected in the BfTGermVet monitoring programme 2004-2006 in Germany. J Antimicrob Chemother 2008, 61:282-285.

32. Meemken D, Cuny C, Witte W, Eichler U, Staudt R, Blaha T: Zum Vorkommen von MRSA bei Schweinen und bei Menschen mit beruflicher Exposition zum Schwein - Erste Ergebnisse einer Studie in Nordwestdeutschland. Dtsch tierärztl Wschr 2008, 115:132-139. in German.

33. Tenhagen BA, Fetsch A, Stührenberg B, Schleuter G, Guerra B, Hammerl JA Hertwig S, Kowall J, Kämpe U, Schroeter A, Bräunig J, Käsbohrer A, Appel B: 
Prevalence of MRSA types in slaughter pigs in different German abattoirs. Vet Rec 2009, 165:589-593.

34. Lee JH: Methicillin (oxacillin)-resistant Staphylococcus aureus strains isolated from major food animals and their potential transmission to humans. App Environ Microbiol 2003, 69:6489-6494.

35. Moon JS, Lee AR, Kang HM, Lee ES, Kim MN, Paik YH, Park YH, Joo YS, Koo HC: Phenotypic and genetic antibiogram of methicillin-resistant staphylococci isolated from bovine mastitis in Korea. J Dairy Sci 2007, 90:1176-1185

36. Schmitz FJ, Krey A, Sadurski R, Verhoef J, Milatovic D, Fluit AC: Resistance to tetracycline and distribution of tetracycline resistance genes in European Staphylococcus aureus isolates. J Antimicrob Chemother 2001, 77:239-246.

37. Monecke S, Berger-Bächi B, Coombs C, Holmes A, Kay I, Kearns A, Linde HJ ÓBrien F, Slickers $P$, Ehricht R: Comparative genomics and DNA-arraybased genotyping of pandemic Staphylococcus aureus strains carrying Panton-Valentine leukocidin. Clin Microbiol Infect 2007, 13:236-249.

38. Goerke C, Wirtz C, Flückiger U, Wolz C: Extensive phage dynamics in Staphylococcus aureus contributes to adaption to the human host during infection. Mol Microbiol 2006, 61:1673-1685.

39. Sommerhäuser J, Kloppert B, Wolter W, Zschöck M, Sobiraj A, Failing K: The epidemiology of Staphylococcus aureus infections from subclinical mastitis in dairy cows during a control programme. Vet Microbiol 2003, 96:91-102.

40. Roberson JR, Fox LK, Hancock DD, Gay JM, Besser TE: Ecology of Staphylococcus aureus isolated from various sites on dairy farms. J Dairy Sci 1994, 77:3354-3364.

41. Zetola N, Francis JS, Nuermberger EL, Bishai WR: Community-acquired meticillin-resistant Staphylococcus aureus: an emerging threat. Lancet Infect Dis 2005, 5:275-286.

doi:10.1186/1297-9716-43-42

Cite this article as: Schlotter et al:: Leukocidin genes lukF-P83 and lukM are associated with Staphylococcus aureus clonal complexes 151, 479 and 133 isolated from bovine udder infections in Thuringia, Germany . Veterinary Research 2012 43:42.

\section{Submit your next manuscript to BioMed Central and take full advantage of:}

- Convenient online submission

- Thorough peer review

- No space constraints or color figure charges

- Immediate publication on acceptance

- Inclusion in PubMed, CAS, Scopus and Google Scholar

- Research which is freely available for redistribution 